\title{
Statistical Relationship between Atmospheric Rivers and Extratropical Cyclones and Anticyclones
}

\author{
YANJUAN GUO ${ }^{\mathrm{a}}$ AND TOSHIAKI SHINODA \\ Department of Physical and Environmental Science, Texas A\&M University-Corpus Christi, Corpus Christi, Texas \\ Bin GuAN AND DUANE E. WALISER \\ Joint Institute for Regional Earth System Science and Engineering, University of California, Los Angeles, and \\ Jet Propulsion Laboratory, California Institute of Technology, Pasadena, California
}

EDMUND K. M. CHANG

School of Marine and Atmospheric Sciences, Stony Brook University, State University of New York, Stony Brook, New York

(Manuscript received 20 February 2019, in final form 16 June 2020)

\begin{abstract}
Statistical relationships between atmospheric rivers (ARs) and extratropical cyclones and anticyclones are investigated on a global scale using objectively identified ARs, cyclones, and anticyclones during 1979-2014. Composites of circulation and moisture fields around the ARs show that a strong cyclone is located poleward and westward of the AR centroid, which confirms the close link between the AR and extratropical cyclone. In addition, a pronounced anticyclone is found to be located equatorward and eastward of the AR, whose presence together with the cyclone leads to strong horizontal pressure gradient that forces moisture to be transported along a narrow corridor within the warm sector of the cyclone. This anticyclone located toward the downstream equatorward side of the cyclone is found to be missing for cyclones not associated with ARs. These key features are robust in composites performed in different hemispheres, over different ocean basins, and with respect to different AR intensities. Furthermore, correlation analysis shows that the AR intensity is much better correlated with the pressure gradient between the cyclone and anticyclone than with the cyclone/ anticyclone intensity alone, although stronger cyclones favor the occurrence of AR. The importance of the horizontal pressure gradient in the formation of the AR is also consistent with the fact that climatologically ARs are frequently found over the region between the polar lows and subtropical highs in all seasons.
\end{abstract}

\section{Introduction}

Atmospheric rivers (ARs) are long, narrow corridors of enhanced water vapor in the troposphere, which transport a large amount of water vapor from the tropics/subtropics to the extratropics (Zhu and Newell 1998; Ralph et al. 2004; Bao et al. 2006). The heavy precipitation and intense wind conditions associated with the ARs exert both beneficial (e.g., replenishing water reservoirs) and detrimental (e.g., causing floods and landslides when abundant, or droughts when deficient)

\footnotetext{
${ }^{a}$ Current affiliation: Earth System Science Interdisciplinary Center, University of Maryland, College Park, College Park, Maryland.
}

Corresponding author: Dr. Yanjuan Guo, yanjuan.guo@noaa.gov impacts on the society (e.g., Ralph et al. 2004; Gimeno et al. 2014; Waliser and Guan 2017) in many regions around the globe. Among them, western North America has been most widely discussed (Ralph et al. 2006; Bao et al. 2006; Neiman et al. 2008a,b; Leung and Qian 2009; Guan et al. 2010, 2013; Ralph and Dettinger 2011; Rutz et al. 2014; Warner et al. 2012, 2015; and many others). Other regions such as continental Europe (e.g., Lavers et al. 2012; Lavers and Villarini 2013; Ramos et al. 2015; Eiras-Barca et al. 2016; Brands et al. 2016; Lavers et al. 2018) and South America (e.g., Viale and Nunez 2011) have been examined as well.

The association of ARs with extratropical cyclones has long been suggested. In the early 1940s, it was already noticed that positions of strong moisture flow correspond closely to the cold fronts of cyclones (Starr 1942; Haurwitz and Austin 1944). Later studies indicated 
that ARs evolve and move with the development of extratropical cyclones and the midlatitude jet (e.g., Newell and Zhu 1994; Zhu and Newell 1994; Ralph et al. 2004; Payne and Magnusdottir 2014). For example, Newell and Zhu (1994) indicate the connection between ARs and atmospheric bombs, which are rapidly developing cyclones with an average intensifying rate of at least $1 \mathrm{hPa} \mathrm{h}^{-1}$ for a period of at least $24 \mathrm{~h}$. More recent studies have directly linked the ARs with the extratropical cyclones and have suggested that ARs are typically associated with the pre-cold-frontal region and are the narrow bands of high water vapor content located within the warm conveyor belt of extratropical cyclones (e.g., Ralph et al. 2006; Bao et al. 2006; Neiman et al. 2011; Catto and Pfahl 2013; Gimeno et al. 2014; EirasBarca et al. 2018). Another study (Dacre et al. 2015) further argued that the ARs are formed by the cold front that sweeps up water vapor in the warm sector as it catches up with the warm front. Note that despite the similarity between the AR and the warm conveyor belt of the cyclone, they are not identical concepts and focus on different aspects of moisture transport (AMS 2017; Dacre et al. 2019). For example, an AR is an Earthrelative airflow, while the warm conveyor belt is a cyclone-relative airflow (Dacre et al. 2019).

Although a close link between ARs and extratropical cyclones has been suggested as above (see also the $A M S$ Glossary definition of ARs; AMS 2017), previous studies were mainly based on case studies of limited number of ARs, or usually focused on certain specific regions and seasons, such as the eastern North Pacific and NH cool season. The general relationship between ARs and extratropical cyclones had not been examined until very recently when long records of objectively detected ARs became available. Eiras-Barca et al. (2018) analyzed the concurrence of ARs and explosive cyclogenesis over the North Atlantic and North Pacific basins for the extended winter months, and found that ARs accompany almost $80 \%$ of explosively deepening cyclones, whereas for nonexplosive cyclones ARs are found only in roughly $40 \%$ of the cases. Zhang et al. (2019) investigated the ARs and extratropical cyclones over the U.S. West Coast during the $\mathrm{NH}$ cool season and indicated that AR intensity is only moderately proportional to extratropical cyclone strength, suggesting that other factors may contribute to determining the AR strength. However, these studies still focused on specific regions and seasons, and analysis on a global domain and in all seasons is desirable.

In addition to the close connection of ARs to extratropical cyclones, recent studies suggest the possible role of anticyclones in generating ARs (Payne and Magnusdottir 2014; Zhang et al. 2019). For example, Payne and Magnusdottir (2014) suggested that the development of anticyclonic Rossby wave breaking in the eastern Pacific Ocean plays a significant role in generating landfalling ARs along the west coast of North America. Zhang et al. (2019) found that the ARs over the U.S. West Coast are usually close to a subtropical/tropical moisture source and include a nearby anticyclone. In addition, Boutle et al. (2010) suggested that the anticyclone could lead to enhanced evaporation of moisture from the ocean surface downstream of the cyclone, favoring the formation of the AR. These studies, however, discussed ARs only over limited regions, such as the west coast of North America (Payne and Magnusdottir 2014; Zhang et al. 2019) and the European continent (Lavers et al. 2018), or in idealized model simulations (Boutle et al. 2010).

In this study, we seek to identify some general relationship between ARs, extratropical cyclones, and anticyclones. The motivation is that, relative to ARs, extratropical cyclones and anticyclones have been much better examined and understood under the relatively mature framework of midlatitude dynamics. The identification and quantification of general relationship between ARs, cyclones, and anticyclones help provide useful insights for understanding the physics related to the ARs. Also, given the fact that the large-scale circulation (e.g., the cyclone and anticyclone) is more accurately represented in forecast models than moisturerelated quantities (e.g., the ARs), our work makes it possible to use the forecast information of cyclones and anticyclones to infer the properties of the forecast ARs.

In this study, to identify the general relationship between ARs, cyclones, and anticyclones, we make use of as many AR, cyclone, and anticyclone samples as possible. Therefore, objectively detected ARs, cyclones, and anticyclones over the globe and spanning over several decades are examined. To obtain the most robust relationships, analyses are carried out for both the globe and different ocean basins, as well as for different seasons, which had not been done in previous studies.

The paper is organized as follows. Section 2 briefly describes the data and method used in this paper. The relationships between the ARs, extratropical cyclones, and anticyclones are explored through composite analysis in section 3 and correlation analysis in section 4 . The main conclusions are summarized and discussed in section 5 .

\section{Data and method}

\section{a. Data}

All of the atmospheric variables used in this study are derived from the European Centre for Medium-Range Weather Forecasts (ECMWF) interim reanalysis (ERAInterim) dataset (Dee et al. 2011). Six-hourly data on a 
$1.5^{\circ}$ by $1.5^{\circ}$ latitude-longitude grid are used. The time period covers from March 1979 to December 2014.

\section{b. Objectively detected AR database}

ARs in the global domain were objectively detected by the algorithm developed by Guan and Waliser (2015) based on characteristics of the integrated water vapor transport (IVT). First, grid cells with enhanced IVT are identified where the IVT intensity exceeds the seasonally and geographically varying 85th percentile, or a fixed limit of $100 \mathrm{~kg} \mathrm{~m}^{-1} \mathrm{~s}^{-1}$, whichever is greater. Then further constraints indicative of AR conditions are applied to identify an AR, including the coherence in IVT direction across individual grid cells, mean IVT (MIVT; i.e., the IVT averaged over all AR grid cells) having a poleward component, consistency between MIVT direction and the AR shape orientation, and geometric requirements (length $>2000 \mathrm{~km}$ and length-to-width ratio $>2$ ). Key features of the ARs identified are recorded at 6-hourly intervals, including the shape of the AR (all the grid cells with AR conditions), the water vapor mass transport by the $A R$, the centroid of the AR, and other parameters.

This global AR archive has been compared to regional AR archives in western North America, Britain, and East Antarctica that were independently conducted by other studies using different techniques, and shows over $\sim 90 \%$ agreement with them in terms of AR landfall dates (Guan and Waliser 2015; Guan et al. 2018; Ralph et al. 2018; Shields et al. 2018). This algorithm was also the first-and so far remains the only-algorithm that has been formally evaluated against field observations (dropsondes) in terms of geometry and intensity of detected ARs, and thus it has often been used as a benchmark by later studies when developing/applying region-specific algorithms in different parts of the world (e.g., Yang et al. 2018; Eiras-Barca et al. 2018; Lakshmi et al. 2019).

Figure 1a shows the global distribution of the frequency of AR events to provide some background information on where AR events are mostly located. Note that in this study an AR event (and cyclone and anticyclone event in later discussions) corresponds to a snapshot of AR condition at every 6-h interval rather than the entire track of AR condition (e.g., Sellars et al. 2017; Zhou et al. 2018). For example, a track of AR condition lasting 3 days will be counted as 12 AR events instead of one event.

To generate the climate distribution map, each AR event at each time step is aggregated and assigned to a $5^{\circ}$ by $5^{\circ}$ grid box according to the longitude and latitude of its centroid. The $5^{\circ}$ by $5^{\circ}$ aggregation ensures adequate sampling per grid box for robustness of the analysis as
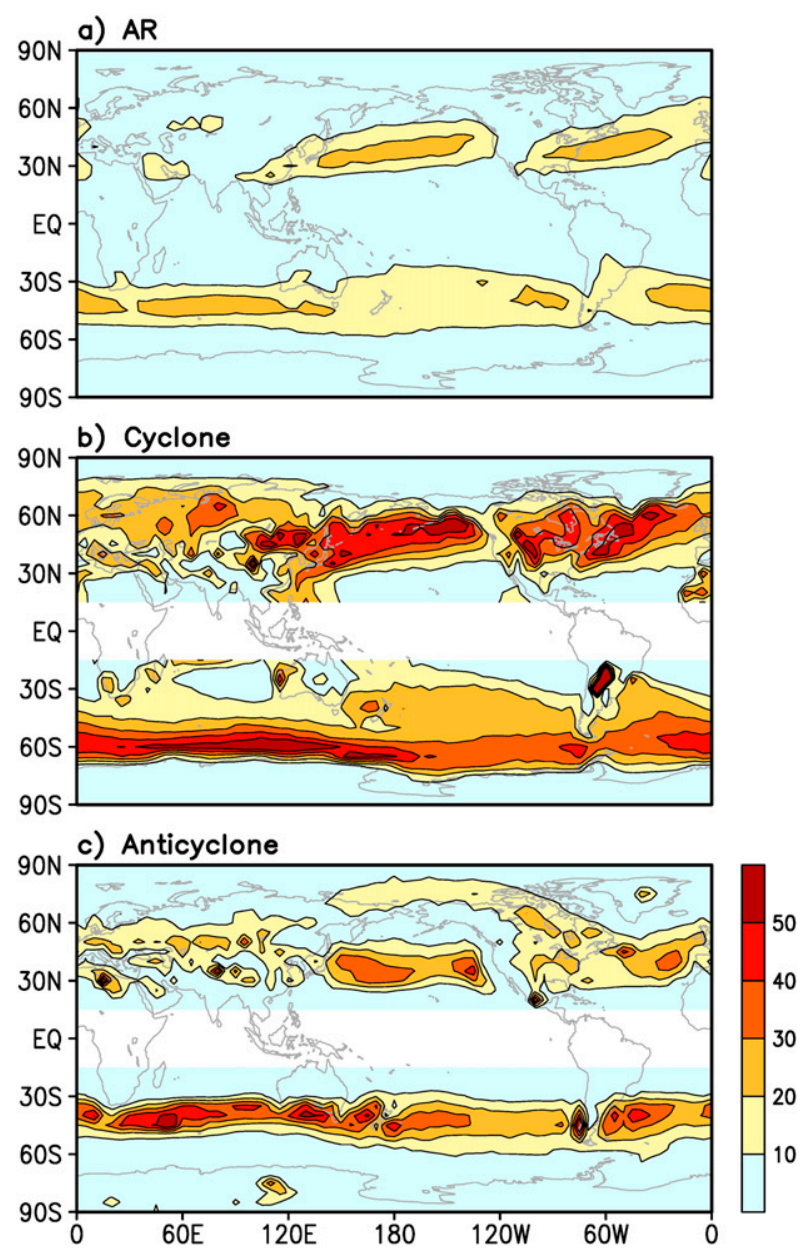

FIG. 1. Global distribution of the annual number of (a) AR, (b) cyclones, and (c) anticyclones averaged during 1979-2014.

well as sufficient spatial resolution. The global distribution of average annual number of AR events during 1979-2014 is displayed in Fig. 1a.

Geographically, ARs are most frequent over the midlatitude oceans as a belt centered at around $40^{\circ} \mathrm{N}$. The AR distribution bear great resemblance to the midlatitude storm tracks, which is consistent with the previous notion that ARs are closely related to extratropical cyclones. Please refer to Guan and Waliser (2015) for a more thorough discussion of the global distribution of ARs and the seasonal and interannual variations within their dataset.

\section{c. Objective tracking of cyclones and anticyclones}

Extratropical cyclones and anticyclones were identified globally by tracking the surface lows (cyclones) and highs (anticyclones) on the mean sea level pressure (MSLP) field using the objective feature tracking tool developed by Hodges (1999). Detailed procedures follow 
those described by Hoskins and Hodges (2002), and are briefly introduced below.

First, a spatial filtering by which only waves with total wavenumber equal to or greater than 5 are retained is applied to the 6-hourly MSLP data to remove the largescale, low-frequency background flow. Local negative MSLP anomalous centers, or the pressure minima, are then identified as the cyclone centers at each time step. Conversely, local positive MSLP anomalous centers, or the pressure maxima, are then identified as the anticyclone centers at each time step. These pressure minima and maxima are then linked together across time steps to form cyclone and anticyclone tracks, respectively. The sets of optimized tracks are obtained by minimizing a cost function with constraints on the track smoothness and the maximum displacement of cyclones and anticyclones between consecutive time steps. In this study, we only make use of tracks with a minimum lifetime of 2 days and a minimum track length of $1000 \mathrm{~km}$ so that the very short-lived and slow-moving local systems that might not be typical extratropical cyclones (e.g., heat lows) are not included. The tracking algorithm provides the position and intensity of a cyclone/anticyclone at every $6 \mathrm{~h}$ for its entire life cycle. The position is indicated by the longitude and latitude of the center of the cyclone/anticyclone, and the intensity is quantified by the absolute value of anomalous pressure at its center, that is, the pressure deficit or surplus for the cyclone or anticyclone relative to the large-scale background pressure. This objective cyclone/anticyclone tracking tool has been widely used for climate studies (Hoskins and Hodges 2002; Donahoe and Battisti 2009; Chang et al. 2012; Guo et al. 2017; and many others).

The global distributions of the extratropical cyclones and anticyclones are shown in Figs. $1 \mathrm{~b}$ and 1c, which correspond to the pattern of the midlatitude storm tracks although the cyclones are more poleward located and the anticyclones are more equatorward located due to their connection to the polar lows and subtropical highs, respectively. Comparing Figs. $1 \mathrm{a}, 1 \mathrm{~b}$, and 1c, it is found that the distributions of the ARs, cyclones, and anticyclones exhibit considerable overlap, which suggests possible coherence among them. It is also apparent that the cyclones are about 2 times as frequent as the ARs, which suggests that not all of the cyclones are associated with ARs.

\section{Relationship between ARs, cyclones, and anticyclones examined by AR composites}

\section{a. Hemispheric AR composites}

As mentioned in the introduction, previous studies examining the relation between the ARs and the extratropical cyclones were mainly based on limited number of events and focused on specific regions. Due to the availability of the multidecade global AR dataset, we are able to construct an AR composite based on unprecedented number of AR events, which enables us to reveal the general large-scale meteorological conditions surrounding the AR.

To examine the general circulation and moisture conditions associated with ARs, MSLP and total column water vapor (TCWV) are composited around the AR centroid using all of the ARs on a global domain during 1979-2014. They are composited over a $100^{\circ}$ longitude by $50^{\circ}$ latitude domain centered at the centroid of ARs (i.e., the IVT-weighted center of the AR; see Guan and Waliser 2015) to show the typical distribution of surface circulation and moisture content around ARs (Fig. 2). The composite is constructed separately for the Northern Hemisphere (NH) and Southern Hemisphere (SH) since the large-scale circulation, as well as many other meteorological conditions, differs considerably in the $\mathrm{NH}$ and the $\mathrm{SH}$ because of differences in their respective landsea distributions. For example, the $\mathrm{SH}$ circulation is much more zonally symmetric compared to that of the NH. To focus on the extratropical regions, only ARs with centroids within the $25^{\circ}-65^{\circ}$ latitude band are used for the composite, which results in about $2 \times 10^{5} \mathrm{AR}$ events for the period of 1979-2014 for each hemisphere (the exact number used for composite is indicated at the upper corner of each plot). Again, it is noted that in this study an AR event is a "snapshot" of the AR track at 6-h intervals.

For the composite of ARs in the NH (Fig. 2a), it is found that a pronounced cyclone is located to the northwest of the AR centroid, and a long narrow band of enhanced TCWV (Fig. 2a) and strong IVT (Figs. 2c,e) - that is, the AR itself-is embedded within the region of the warm conveyor belt of the cyclone. These features are consistent with the notion in previous studies that the $\mathrm{AR}$ is closely associated with the extratropical cyclone and is usually formed within the warm conveyor belt of the extratropical cyclone (e.g., Zhu and Newell 1994; Dacre et al. 2015; Eiras-Barca et al. 2018). Interestingly, in addition to the cyclone, a pronounced anticyclone to the southeast of the AR centroid is also evident. The presence of the cyclone to the northwest of the AR centroid and the anticyclone to its southeast results in a narrow corridor of strong horizontal pressure gradient (Fig. 2g) that collocates with the area of strong TCWV (Fig. 2a) and strong low-level winds (Fig. 2g) giving rise to strong IVT (Figs. 2c,e), suggesting that the anticyclone is important in producing the AR condition. Convergence of moisture flux (Fig. 2c) also shows a broad region of moisture divergence to the southeast of the anticyclone, suggesting that this is an important 

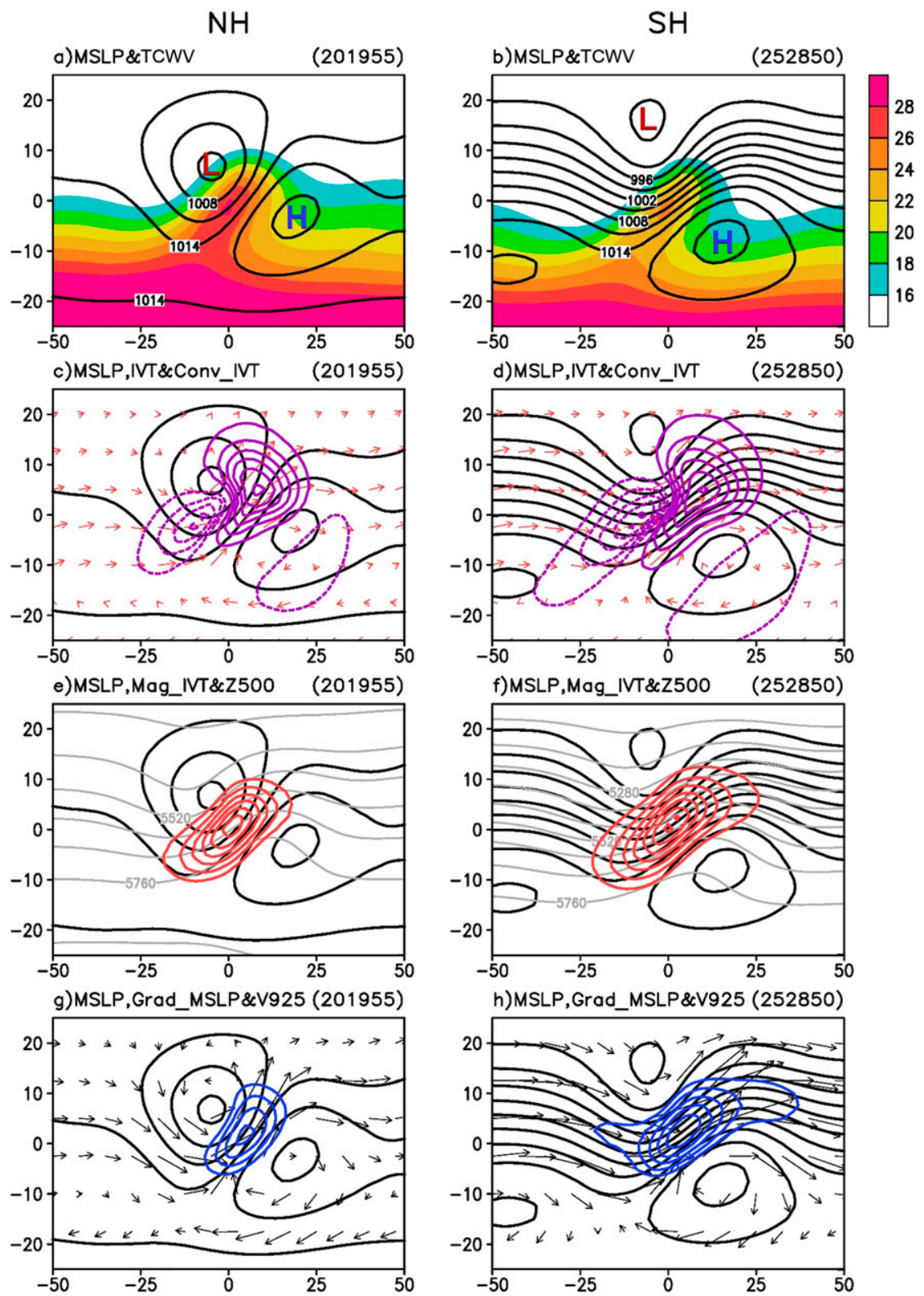

FIG. 2. For the (left) NH and (right) SH, composites of MSLP (black solid contours in all panels; hPa) and other important atmospheric parameters over a $100^{\circ}$ longitude by $50^{\circ}$ latitude box around the centroids of ARs during 1979-2014. In addition to the MSLP, (a),(b) TCWV (shading; $\mathrm{kg} \mathrm{m}^{-2}$ ); (c),(d) IVT vector (red arrows; $\mathrm{kg} \mathrm{m} \mathrm{s}^{-1}$ ) and convergence of horizontal IVT (purple contours, solid is convergence and dashed is divergence; $\mathrm{kgs}^{-1}$, interval is $0.00002 \mathrm{~kg} \mathrm{~s}^{-1}$ and the zero line is omitted); (e),(f) magnitude of IVT (red solid contours; $\mathrm{kg}$ $\mathrm{m} \mathrm{s}^{-1}$, interval is $50 \mathrm{~kg} \mathrm{~m} \mathrm{~s}^{-1}$, starting from $150 \mathrm{~kg} \mathrm{~m} \mathrm{~s}^{-1}$ ) and geopotential height at $500 \mathrm{hPa}$ (gray contours; $\mathrm{m}$, interval is $80 \mathrm{~m}$ ); and $(\mathrm{g}),(\mathrm{h})$ magnitude of horizontal MSLP gradient (blue solid contours; $\mathrm{hPa} \mathrm{m}{ }^{-1}$, interval is $0.0004 \mathrm{hPa} \mathrm{m}^{-1}$, starting from $0.0008 \mathrm{hPa} \mathrm{m}^{-1}$ for the $\mathrm{NH}$ and $0.0012 \mathrm{hPa} \mathrm{m}^{-1}$ for the $\left.\mathrm{SH}\right)$ and wind vector at $925 \mathrm{hPa}\left(\mathrm{m} \mathrm{s}^{-1}\right)$ are shown. Only ARs with center within the $25^{\circ}-65^{\circ}$ latitude bands are used for the composite, and the number used for each plot is indicated at the top-right corner. Note that the plots for the SH are flipped upside down such that the direction of the South Pole is upward. 
moisture source region, further confirming the importance of the anticyclone. Other atmospheric parameters such as the geopotential height (Fig. 2e), lower- and upper-level divergence, and vorticity (not shown) all reveal the coherent structure around the centroid of ARs: a prominent cyclone to the northwest and an anticyclone to the southeast.

The same composite analyses are performed for the $\mathrm{SH}$, and results are shown in Figs. 2b, 2d, 2f, and $2 \mathrm{~h}$. To better compare with the NH counterparts, the plots for the $\mathrm{SH}$ are shown with the South Pole toward the top of the figure. It can be seen that the major findings based on the $\mathrm{NH}$ composites are all evident for the SH cases except that stronger zonal flows are present relative to the NH counterparts. This is because the climatological mean surface westerly jet is much stronger and the circulation is more zonally symmetric in the $\mathrm{SH}$ than that in the $\mathrm{NH}$ as the result of the difference in land-ocean distribution in the two hemispheres.

Note that it is also found that the individual cyclones and anticyclones reasonably cluster around the composite cyclone and anticyclone respectively (not shown), and thus the composite cyclone and anticyclone are robust.

\section{b. AR composites in different regions}

The results highlighted in the previous section were performed for ARs in the entire $\mathrm{NH}$ and $\mathrm{SH}$ (i.e., all longitudes combined). It is not clear whether AR characteristics and structures obtained from these analyses are common features in different ocean basins.

To examine the regional difference of AR characteristics, the same AR composites as shown in Fig. 2a are formed for individual ocean basins that have been further partitioned into the eastern and western parts (Fig. 3). Overall, key features found in the hemispheric composites (Fig. 2) are also found in all the composites in different basins: ARs are accompanied by a cyclone (cyclonic circulation in most of $\mathrm{SH}$ cases) at the western poleward side and an anticyclone at the eastern equatorward side. The area of strong pressure gradient between the cyclone and anticyclone collocates with the narrow band of strong TCWV. This reinforces the idea that the AR composite is characterized by the cyclone-AR-anticyclone three-body system, and both the cyclone and anticyclone are important in generating the AR. Nevertheless, it is also noted that in the SH the zonal circulation is much stronger than that in the $\mathrm{NH}$ so that the composite cyclone often appears as a strong trough. However, a closed cyclone will be present if the large-scale background flow is removed.
While the basic spatial structure of the AR composites is similar in all basins, there are some notable differences. For example, in the $\mathrm{NH}$ composites, the composite cyclones in the eastern portion of the North Pacific and North Atlantic Oceans are stronger than those in the western portion: 1002 versus $1005 \mathrm{hPa}$ in the North Pacific, and 1002 versus $1008 \mathrm{hPa}$ in the North Atlantic in terms of center low pressure; the composite anticyclones are also stronger in the eastern part of the basins. This leads to stronger horizontal pressure gradient between the cyclone and anticyclone in the eastern portion of the basins that generates narrower band of water vapor transport even though the mean water vapor content is higher in the western part of the basins given the existence of the "warm pool" in the western portion of the $\mathrm{NH}$ ocean basins.

In the $\mathrm{SH}$, the differences between the western and eastern portions of the basins are less apparent as those in the $\mathrm{NH}$ although the TCWV is still slightly higher in the west. This is likely due to the more zonally symmetric meteorological conditions in the SH compared to those in the NH.

\section{c. AR composites with different strengths}

The AR structure and characteristics discussed in the previous sections are based on the analysis of all AR events with different strength. In this section, we further composite the ARs according to their intensity (the mean IVT of the AR) to examine whether the commonly found features of the AR composite are robust or sensitive to the AR intensity. Figure 4 shows the AR composites using the ARs with strength of top $20 \%$, middle $20 \%$, and bottom $20 \%$, respectively. Overall, the similar cyclone-AR-anticyclone spatial pattern is found in all three intensity categories. The difference between the $\mathrm{NH}$ and $\mathrm{SH}$ is also similar to that discussed in previous sections.

In comparing the strongest ARs with the weakest, it is apparent that strong ARs are accompanied by stronger pressure gradients, which will be demonstrated more quantitatively in next section. In addition, strong ARs have much higher TCWV than weak ARs, which is consistent with previous study that showed the composite ARs based on different strengths in the northeast Pacific (Zhang et al. 2019), highlighting the importance of moisture availability in determining the strength of the ARs. Strong ARs also show stronger moisture convergence to the east of the cyclone, and a broad region of moisture divergence to the south and east of the anticyclone, again demonstrating the importance of the anticyclone in generating the strong moist flow feeding the AR. It is also found that strong ARs are mainly located over the oceans and weak ARs are mainly found 

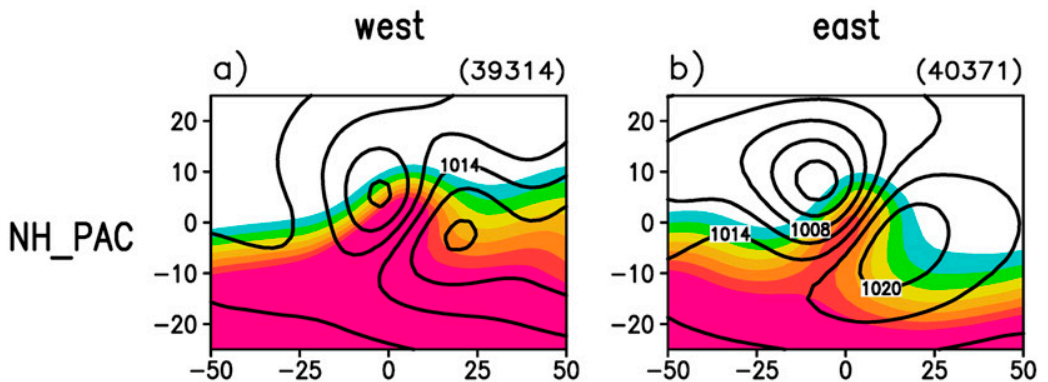

c)

(23067)

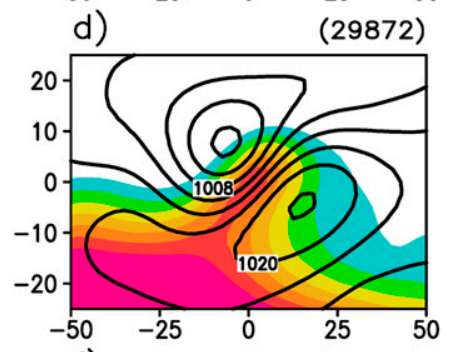

NH_ATL
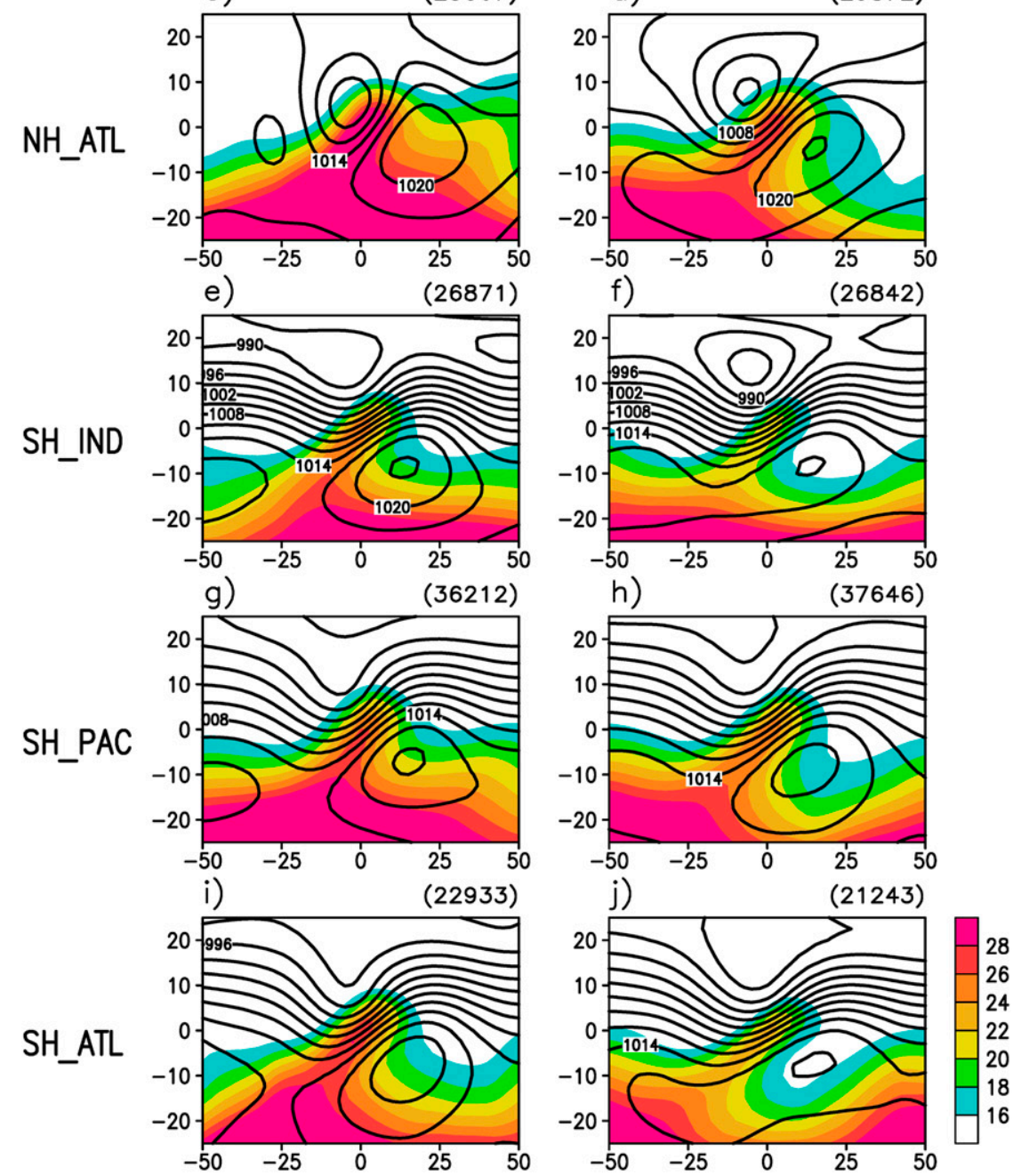

FIG. 3. The same AR composites as in Fig. 2, but using AR events over different ocean basins: the (a) western and (b) eastern NH Pacific, (c) western and (d) eastern NH Atlantic, (e) western and (f) eastern SH Indian Ocean, (g) western and (h) eastern SH Pacific, and (i) western and (j) eastern SH Atlantic. The composites of MSLP (black solid contours; hPa) and TCWV (shading; $\mathrm{kg} \mathrm{m}^{-2}$ ) are shown. 

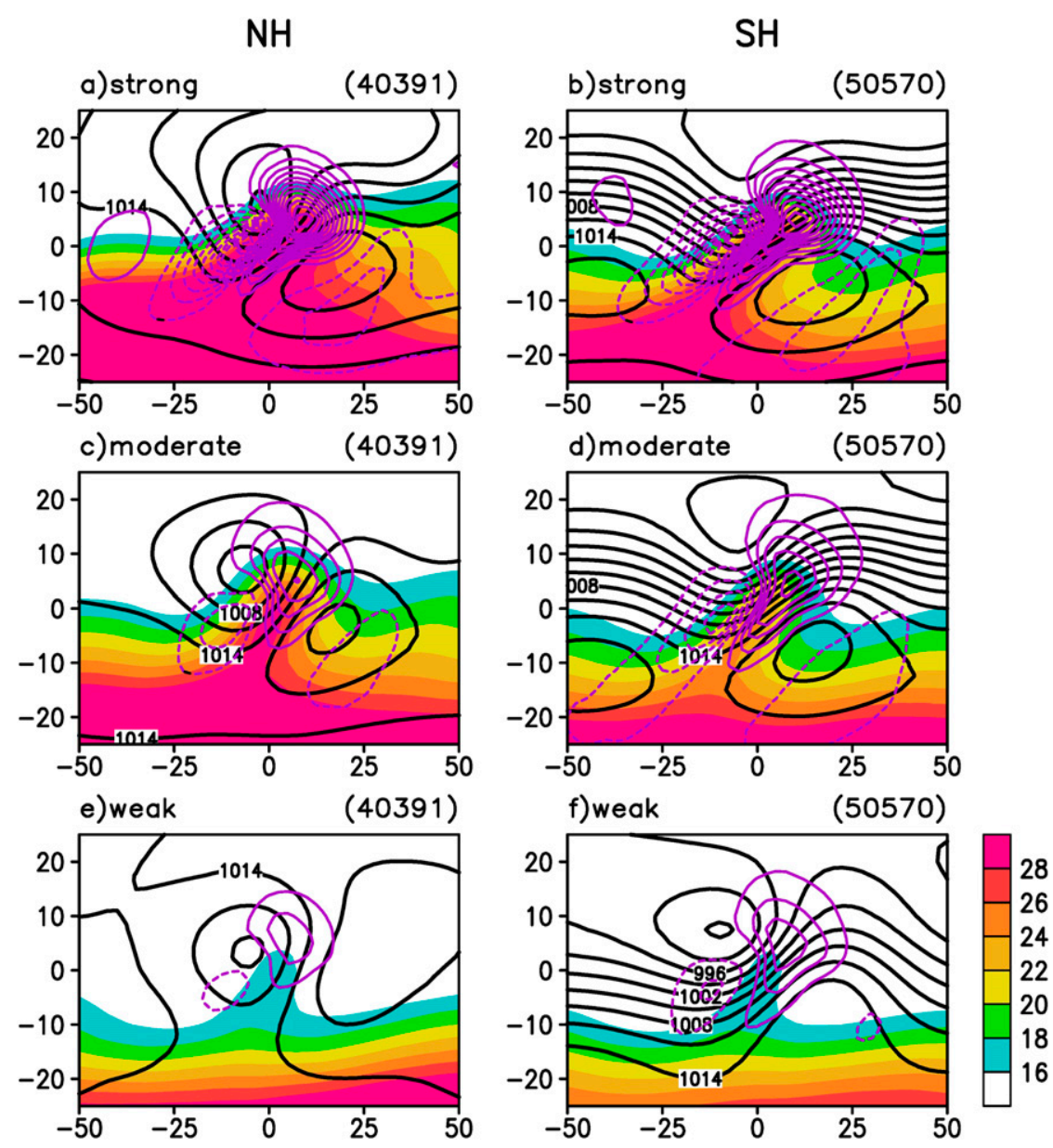

FIG. 4. The same AR composites as in Fig. 2, but for AR cases with different strength: (a),(b) strong, (c),(d) moderate, and (e),(f) weak. Strong cases use AR events with strength within the top $20 \%$, moderate is for $40 \%-60 \%$, and weak is for the bottom $20 \%$. The composites of MSLP (black solid contours; hPa), TCWV (shading; $\mathrm{kg} \mathrm{m}^{-2}$ ), and convergence of IVT (purple contours, solid is convergence and dashed is divergence; $\mathrm{kg} \mathrm{s}^{-1}$, interval is $0.00002 \mathrm{~kg} \mathrm{~s}^{-1}$ and the zero line is omitted) are shown.

either over land or at high latitudes (not shown because of the length limit of this paper), thus explaining the TCWV difference in the composites.

\section{Correlation of $A R$ intensity with cyclone and anticyclone intensity, and the cyclone-anticyclone pressure gradient}

In the previous section, the composite analyses of ARs in both hemispheres, in different ocean basins, and with different strengths all confirm that the spatial structure around ARs is characterized by the cycloneAR-anticyclone three-body system. The importance of the cyclone to the AR, which has been widely discussed in previous studies, is further confirmed in these composite results. Furthermore, our results indicate that the anticyclone is also a necessary component to the AR.
We argue that the presence of the anticyclone helps to generate a stronger horizontal pressure gradient than does the cyclone alone, and this leads to stronger poleward winds and enhanced water vapor transport along a narrow corridor between the cyclone and anticyclone (i.e., the AR condition). In this section, the above hypothesis is further examined by examining the correlations between the intensity of the AR with the following quantities: the intensity of the cyclone associated with the AR, the intensity of the associated anticyclone, and the magnitude of the horizontal pressure gradient between the cyclone and anticyclone. The concept of a cyclone/anticyclone that is associated with an AR is defined in section 4a below. All pairs of ARs and associated cyclones/anticyclones over the globe during 19792014 are used in the correlation calculations. The AR intensity is measured by the MIVT, which is the IVT 

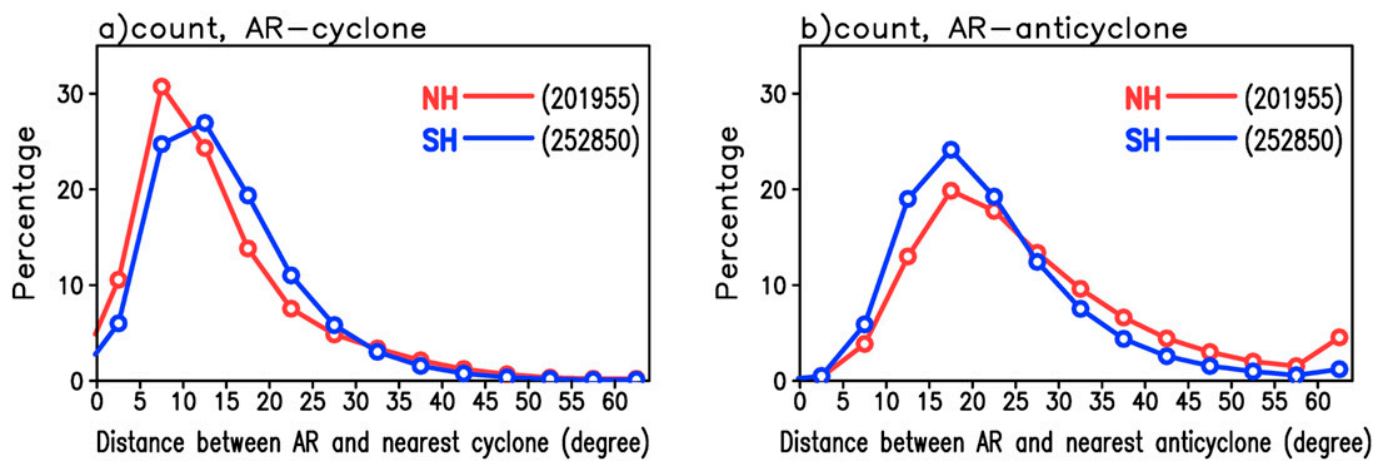

FIG. 5. Distributions of the number of ARs as a function of the distance between the AR centroid and the center of its nearest (a) cyclone and (b) anticyclone (degrees on the great circle), which are normalized by their corresponding total numbers for each case. The total numbers are listed in the parentheses at the top-right corner of the plot. The NH and SH cases are plotted in red and blue, respectively.

averaged over all grid points satisfying AR condition for this AR event (refer to section 2b). The intensity of the cyclone/anticyclone is measured by the absolute value of the pressure anomaly at the center of the cyclone/ anticyclone (section 2c). The magnitude of the horizontal pressure gradient between the cyclone and anticyclone is approximated by the horizontal pressure gradient at the AR centroid. By examining how well the AR intensity is correlated with the intensity of the associated cyclone and anticyclone, as well as the pressure gradient between them, the importance of the cyclone or anticyclone alone, or the combined role of both, to the AR can be inferred.

\section{a. Pairing ARs with cyclones and anticyclones}

The concept of a cyclone/anticyclone that is associated with an AR as well as how to identify it is introduced in this section.

First, the identification of the cyclone associated with an AR is described. In this study, the cyclone associated with an AR is defined as the nearest cyclone around this AR. Theoretically, a nearest cyclone can always be found for any AR. However, if the nearest cyclone of an $\mathrm{AR}$ is quite far away from the AR, the association between them is not certain, and we should not pair them together. Because of this concern, we first examined the histogram of distance between the AR and its nearest cyclone (Fig. 5a), which is calculated as the great circle distance between the AR centroid and the cyclone center. It is found that, most frequently, an AR has its nearest cyclone within $5^{\circ}-15^{\circ}$ (about $500-1500 \mathrm{~km}$ ) of the radius of its centroid, and the majority of the nearest cyclones (about $93 \%$ combining both $\mathrm{NH}$ and $\mathrm{SH}$ cases) are within $30^{\circ}$ of the radius. Here, we use $30^{\circ}$ as the threshold distance and assume that if the distance between an AR and its nearest cyclone is smaller than $30^{\circ}$ it is very likely that they are physically associated. Thus, they are paired together, and the nearest cyclone to the AR is called the "AR-paired cyclone." Although this threshold is arbitrary, our results are not sensitive to this threshold. Note that the ARs are often thousands of kilometers in length (Guan and Waliser 2015) and thus the centroids could be located a few thousand kilometers from the center of cyclones. Also note that here the distance of the cyclone to the AR is the only constraint used to determine the AR-paired cyclone. Applying extra constraints such as using only cyclones in certain directions of an AR guarantees that the selected cyclones are safely associated with the AR, but at the same time discards some cyclones that should be kept. Here we choose not to apply these relatively subjective constraints. Nevertheless, qualitatively the results for the following correlation analysis are not sensitive to additional selection criteria.

Based on the definition of AR-paired cyclone described above, the number of ARs (and the number of AR-paired extratropical cyclones) is about half of the number of all cyclones. When compositing MSLP relative to the cyclone center using only AR-paired cyclones, an anticyclone toward the eastern and equatorward side of the cyclone is still present (Figs. 6a,c), whereas in the MSLP composite using all the cyclones (Figs. 6b,d) or cyclones not close to an AR (not shown) the anticyclone is not observed. This further confirms that the anticyclone to the downstream equatorward side of the cyclone is an essential component in generating the AR condition, and this anticyclone is not a general feature accompanying all cyclones.

In a similar manner, an AR-paired anticyclone is defined. Figure $5 \mathrm{~b}$ shows the distribution of the distance between an AR and its nearest anticyclone. The peak distance is found around $15^{\circ}-20^{\circ}$. Given the fact that 

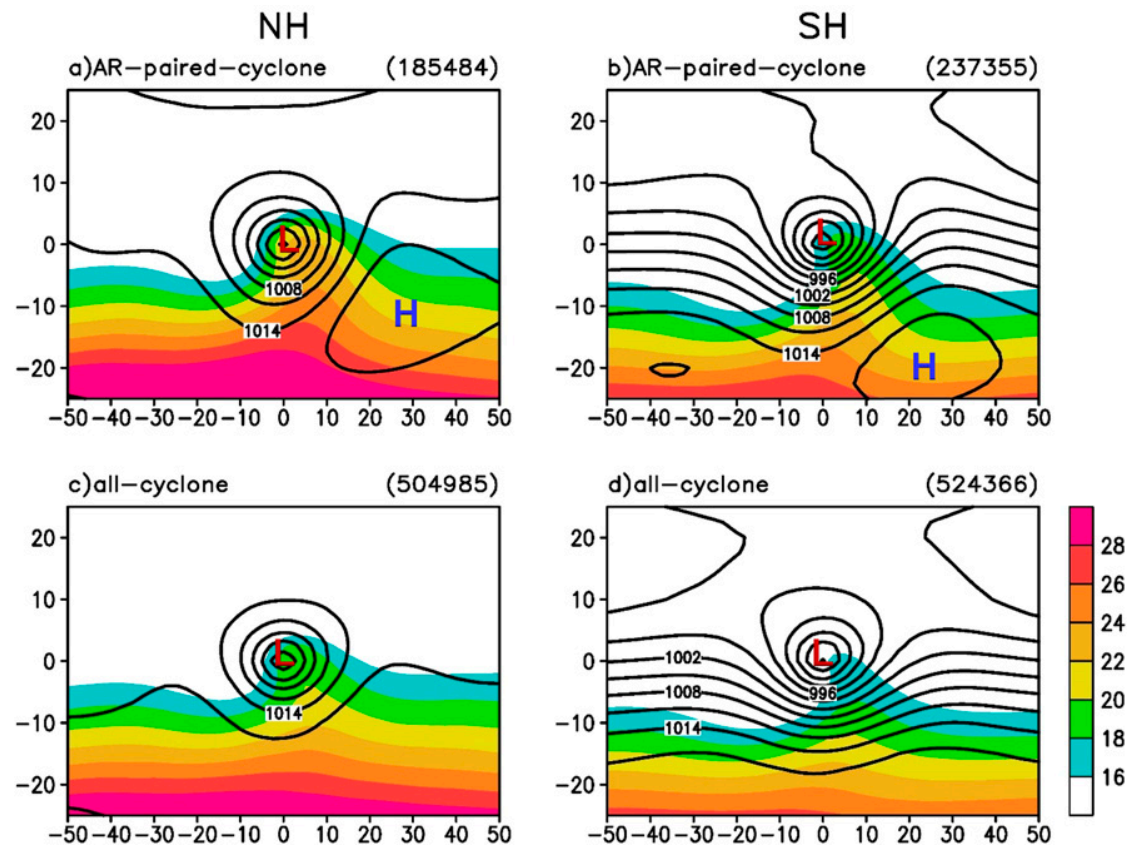

FIG. 6. Similar to Figs. 2a and 2b, but showing cyclone composites, which are composited with respect to the centers of cyclones using (a),(b) the AR-paired cyclones only and (c),(d) all of the cyclones for (left) $\mathrm{NH}$ and (right) SH cases. MSLP is black solid contours (hPa, interval is $3 \mathrm{hPa}$ ), and TCWV is color shaded $\left(\mathrm{kg} \mathrm{m}^{-2}\right)$. Cyclones with center within the $25^{\circ}-65^{\circ}$ latitude band and during 1979-2014 are used. The number of cyclones used for each plot is indicated at the top-right corner. Note that the plots for the $\mathrm{SH}$ are flipped upside down such that the direction of the South Pole is upward.

anticyclones are usually larger in size than cyclones, and composites in Figs. 2-4 show that the composite anticyclone is located a bit farther away from the AR centroid than the composite cyclone, here we use $40^{\circ}$ as the cutoff distance to determine the "AR-paired anticyclone," which includes about $89 \%$ of the nearest anticyclones in Fig. 5b when combining both $\mathrm{NH}$ and $\mathrm{SH}$ cases. Again, qualitatively our results are not sensitive to the cutoff distance.

After identifying the AR-associated cyclones/anticyclones, their geographical distribution together with the ARs are shown in Fig. 7. Regions of active ARs are found in the North Pacific and Atlantic around $30^{\circ}-40^{\circ} \mathrm{N}$ and in the $\mathrm{SH}$ around $30^{\circ}-40^{\circ} \mathrm{S}$.

While the areas of active cyclone and anticyclones overlap with the active AR regions (Fig. 7a), the maximum frequency of cyclones is generally found at the poleward side of the areas of active ARs, and the maximum frequency of anticyclones is generally located equatorward of the areas of active ARs. The difference in location between the AR-paired cyclones and anticyclones is shown in Fig. 7b, confirming that AR-paired cyclones are located poleward of AR-paired anticyclones.

These relative locations of active ARs, cyclones, and anticyclones shown in Fig. 7 are consistent with the composite analyses described in previous sections. As described above (e.g., Fig. 2), an AR is usually found between the cyclone on its western poleward side and the anticyclone on its eastern equatorward side. Hence it is expected that ARs frequently develop between the areas with active cyclone and anticyclone.

\section{b. Correlations between ARs, cyclones, anticyclones, and pressure gradient}

Figures $8 \mathrm{a}$ and $8 \mathrm{~b}$ show the correlation between the $\mathrm{AR}$ intensity and the intensity of the paired cyclone in the NH and SH. The AR intensity is measured by its MIVT, while the cyclone intensity is measured by the absolute value of anomalous MSLP at the cyclone center. While the AR intensity is strongly subject to moisture supply, in this study we focus on examining the dynamical factors impacting the AR intensity through examination of the large-scale circulation (in terms of MSLP) around the AR. To mitigate the impact due to the difference in the background moisture content, which decreases rapidly from the equator to higher latitudes, we separate the correlation calculations to every $5^{\circ}$ latitude band between $25^{\circ}$ and $65^{\circ}$. It is found that the AR intensity is positively correlated with the intensity of its paired cyclone in the $\mathrm{NH}$, although the correlation 


\section{a) AR, cyclone \& anticyclone}

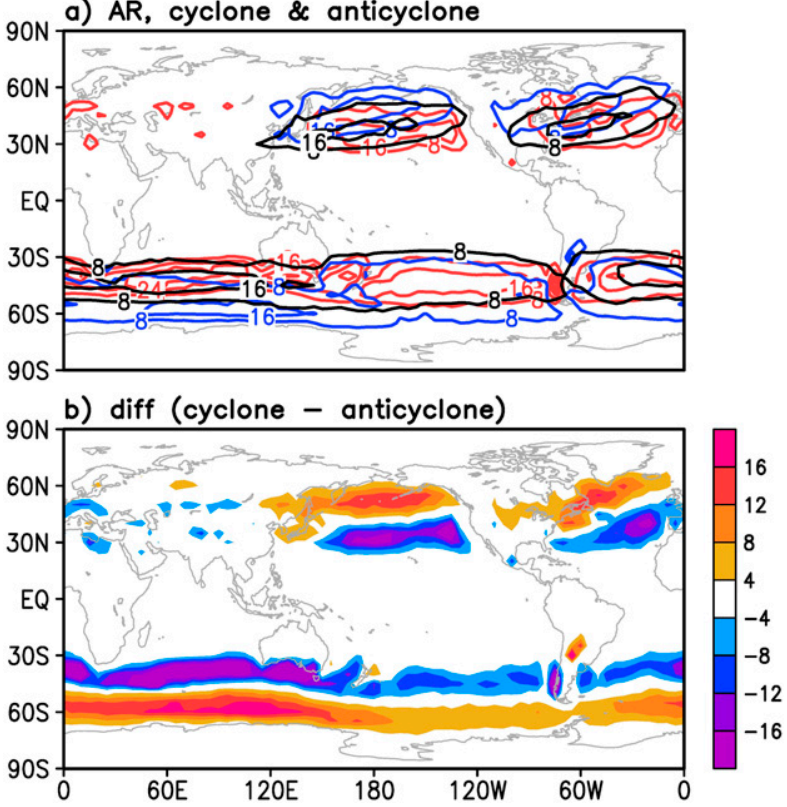

FIG. 7. Global distribution of the annual number of the ARs, paired cyclones, and paired anticyclones averaged during 19792014. Shown are (a) all three quantities (black: AR; blue: cyclone; red: anticyclone) and (b) the difference between the cyclones and anticyclones.

values are small $(0.1-0.2)$, but poorly correlated in the SH: near zero or even negative. The correlations between the AR intensity and the intensity of the paired anticyclone are shown in Figs. 8c and 8d, which are overall very weak.

Figures $8 \mathrm{e}$ and $8 \mathrm{f}$ show correlations between the AR intensity and the magnitude of the horizontal pressure gradient at the AR centroid. The correlations are between 0.2 and 0.3 for most latitudinal bands in both hemispheres, which are much higher than those with cyclone/anticyclone intensity for all latitudes. The average correlation for eight bands between $25^{\circ}$ and $65^{\circ}$ is 0.25 for the $\mathrm{NH}$ and 0.24 for the SH. Given the large number of AR events (on the order of $10^{4}$ or more for each $5^{\circ}$ latitude band), these correlations are highly significant $(p<0.001$ based on the Student's $t$ test), suggesting that horizontal pressure gradient is one of the primary factors that determine the AR intensity.

The correlation analysis is further partitioned for different seasons (Fig. 9) since the background moisture content exhibits prominent seasonal variations. A significant seasonal variation is found in the correlations, especially for the $\mathrm{NH}$ : the correlation tends to be higher in boreal winter than the boreal summer, while the transitional seasons are in between. The seasonal variation is smaller in the $\mathrm{SH}$ than that in the $\mathrm{NH}$, which is likely related to the smaller seasonal variation in the meridional temperature gradient and storm track activity reported in previous studies (Trenberth 1991). In addition to the seasonal variation, it can be seen that the correlation values are systematically larger than those when data from all seasons are taken together (Fig. 8), likely because there is less variation in moisture content within a single season. For example, most of the correlations between the AR intensity and the magnitude of the horizontal pressure gradient are $0.3-0.4$, which are highly significant, and much larger than those with the cyclone/anticyclone intensities. The correlations between AR intensity and cyclone/ anticyclone intensity in the $\mathrm{NH}$ are also higher than those for all seasons. Nevertheless, the correlations of AR intensity with the cyclone/anticyclone in the $\mathrm{SH}$ are still poor.

The above correlation analysis suggests that while a midlatitude AR is almost always associated with a cyclone, the AR intensity is better correlated with the magnitude of horizontal pressure gradient than with the cyclone intensity. Since the magnitude of the pressure gradient depends on the intensity of both cyclone and anticyclone as well as the distance between them, our results further confirm the importance of the anticyclone: the presence of the anticyclone helps generate stronger horizontal pressure gradient compared to the cyclone alone, which leads to enhanced water vapor transport along a narrow corridor between the cyclone and anticyclone (i.e., the AR condition). Note that the anticyclone could also lead to enhanced downstream evaporation of moisture from the ocean surface, which is then transported toward the warm conveyor belt of the cyclone, thus favoring the formation of the AR (Boutle et al. 2010).

In this study the analysis has focused on the dynamical factors contributing to the AR intensity. Note that moisture-related processes also play important roles in determining the AR intensity. In Figs. 9g and 9h we show the correlation between AR intensity and TCWV at the AR centroid. The correlation reaches values of up to $0.6-0.7$ in the $\mathrm{NH}$ and is generally higher than the correlation of AR intensity with the dynamical variables, except in the SH midlatitudes. While these correlations suggest that moisture availability is clearly important as we have emphasized all along, Figs. 2-4 show that the moisture at the centroid is brought there by the strong pressure gradient between the cyclone and anticyclone, and thus the value of TCWV at the AR centroid cannot be considered as independent of the dynamical variables. The combined impacts and interactions between large-scale dynamics and moist processes should be examined further in future studies.

\section{c. Implication of horizontal pressure gradient to the prevailing AR location}

Up to now, the importance of the anticyclone, and thus the strong horizontal pressure gradient between the 
$\mathrm{NH}$

a)AR MIVT \& Cyclone Intensity
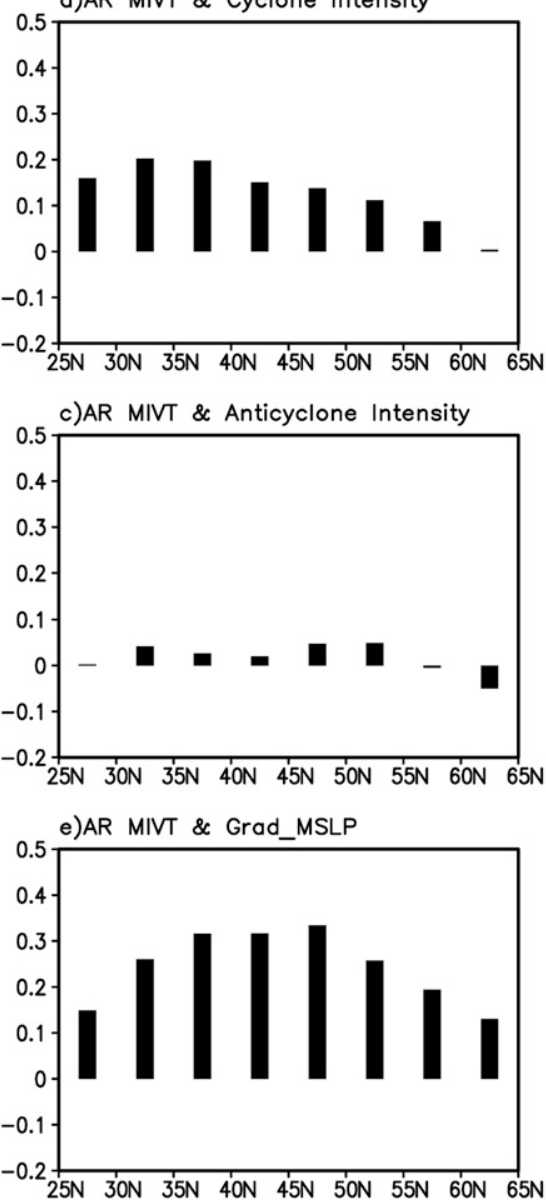

$\mathrm{SH}$

b)AR MIVT \& Cyclone Intensity

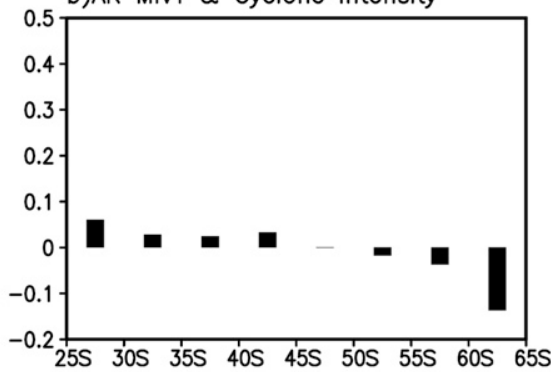

d)AR MIVT \& Anticyclone Intensity
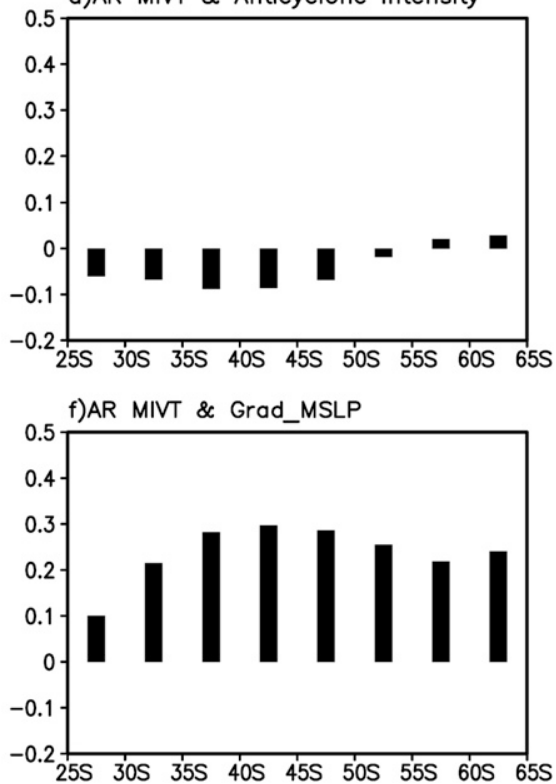

FIG. 8. Correlations between the AR intensity (measured by the MIVT) and the intensity of the AR-paired (a),(b) cyclone and (c),(d) anticyclone (measured by the absolute value of anomalous MSLP at cyclone or anticyclone center), and (e),(f) the magnitude of horizontal pressure gradient at the AR centroid, all for the (left) $\mathrm{NH}$ and (right) $\mathrm{SH}$. Correlations are calculated using $\mathrm{AR}$ events within every $5^{\circ}$ latitude band from $25^{\circ}$ to $65^{\circ}$.

cyclone and anticyclone, in the generation of the ARs has been demonstrated. The results are based on composite and correlation analysis of individual ARs. Here, we will show that the importance of the pressure gradient can be also observed in the climatology by examining the seasonal variation in the distribution of ARs and its relationship to the large-scale mean flow. Given that AR intensity is significantly correlated with the pressure gradient, and AR shape (i.e., all grid cells an AR occupies) is defined based on a minimum IVT threshold (see section 2a), we expect that AR frequency should be modulated by the strength of the large-scale pressure gradient.

The climatological AR number for each season is shown in Fig. 10, together with the large-scale climatological mean flow in terms of mean MSLP. In the NH, the AR number is highest in winter (Fig. 10a), both in the Pacific and the Atlantic. With respect to the mean flow, the ARs are located along the belt of strong pressure gradient between the subtropical highs and the polar lows, generally on the northwestern fringe of the subtropical highs in both basins. A comparison of the four seasons shows that the pressure gradient is strongest in winter. This, together with the strong cyclone and anticyclone activity in winter, frequently provides the strong pressure gradient that is required for the existence of ARs discussed above, consistent with the high AR number in this season. One point to note is that the maximum in AR number is located toward the equatorward side of the strong mean pressure gradient. We hypothesize that this could be due to higher temperatures and higher TCWV toward the south. As discussed 
$\mathrm{NH}$
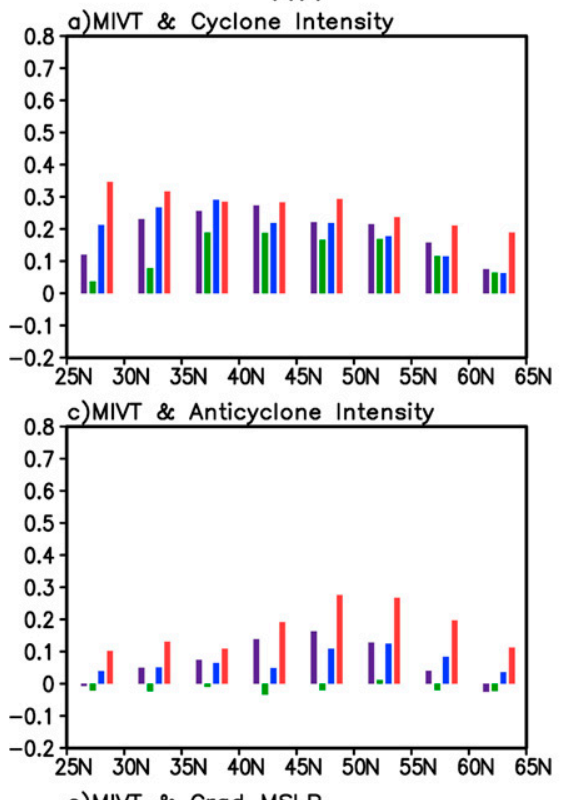

$\mathrm{SH}$
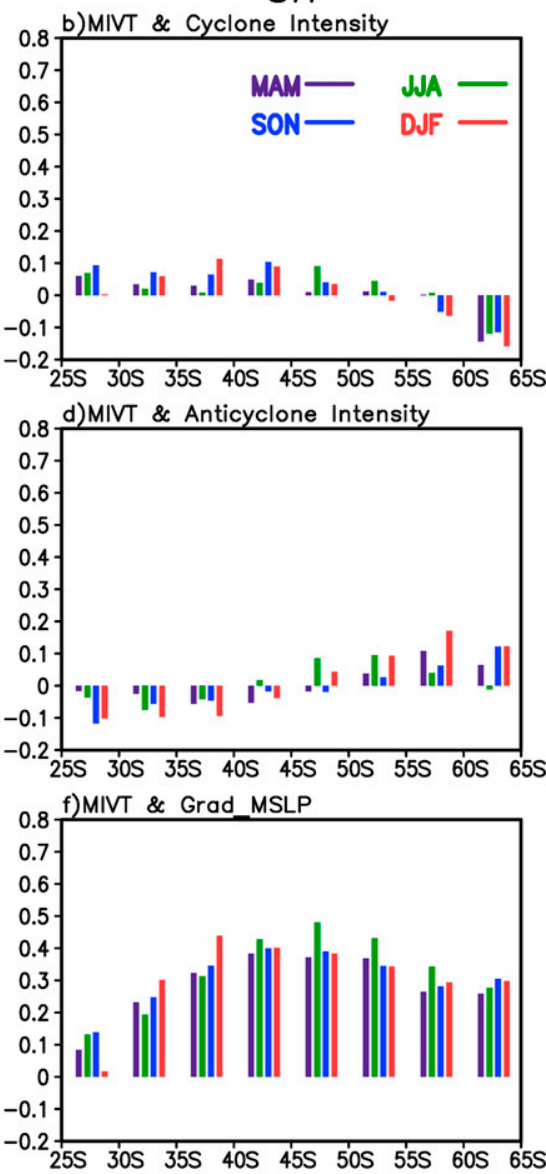

0.8 h)MIVT \& TCWV

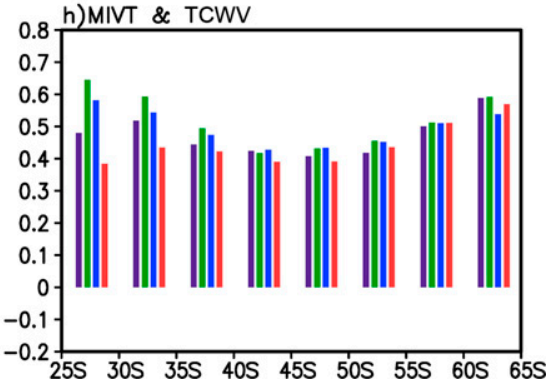

FIG. 9. As in Fig. 8, but separated for different seasons: December-February (red), MarchMay (purple), June-August (green), and September-November (blue). In addition, the correlations between the AR intensity (MIVT) and TCWV at the AR centroid for the (g) $\mathrm{NH}$ and (h) $\mathrm{SH}$ are shown.

in previous sections (e.g., Fig. 4), it appears that the AR distribution is affected not only by the location where the pressure gradient is strongest, but also by the availability of high water vapor content. In this study we focus on the dynamical aspects related to ARs and will investigate the relationship with water vapor content in future studies. Nevertheless, the fact that ARs are not most frequent where TCWV is highest (i.e., in the tropics) but rather are most frequent over regions where there is both high TCWV and strong pressure gradient suggests that both dynamical and thermodynamical factors are important in determining the distribution of ARs.

In NH spring, the AR number decreases slightly in both basins and ARs migrate slightly poleward in the Pacific (Fig. 10b). This is consistent with the reduction in pressure gradient and poleward migration of the subtropical highs and polar lows in this season. Over the Atlantic, while the pressure gradient becomes weaker, the southwest-northeast tilt becomes less pronounced, likely explaining why the AR distribution does not move 

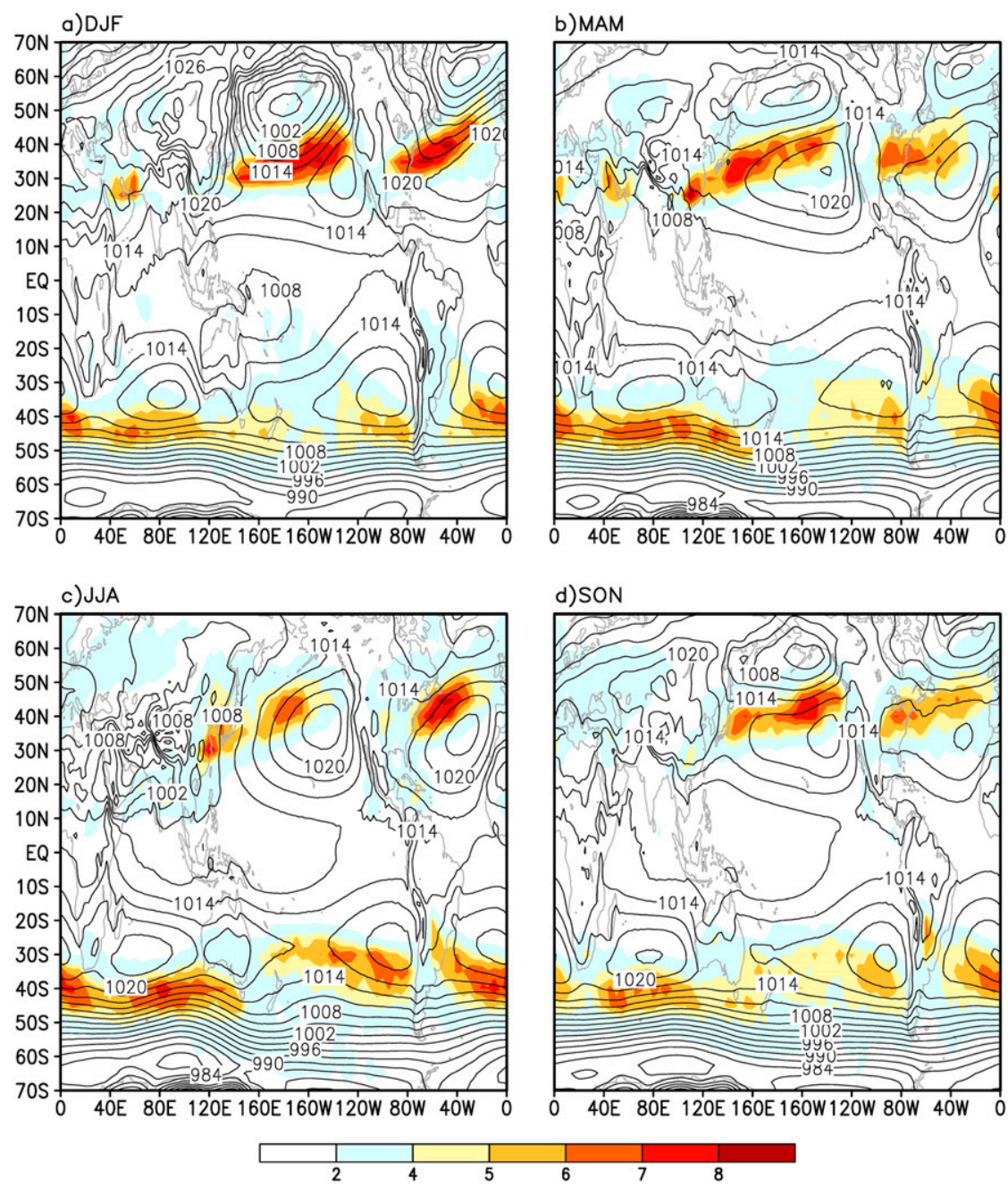

FIG. 10. Seasonal mean AR number (shading) and MSLP (contours; hPa) for (a) DecemberFebruary, (b) March-May, (c) June-August, and (d) September-November averaged during 1979-2014.

poleward in the eastern part of this basin. In summer, the pressure gradient in the Pacific continues to decrease with the Aleutian low nearly disappearing, consistent with the further decrease in AR number there. On the other hand, the gradient in the Atlantic is still maintained and becomes more tilted, likely explaining the stronger tilt in the AR distribution relative to spring. In addition, increased moisture content in the absence of a reduction in pressure gradient likely contributes to the increase in AR number over the Atlantic compared to spring. In autumn, the AR distribution again shifts equatorward and the distribution is relatively similar to that in spring.

In the $\mathrm{SH}$, seasonal variations are smaller but there is still a hint that AR number is also largest in austral winter (June-August). Again, in all four seasons, AR number generally peaks in regions with strong pressure gradient poleward of the subtropical anticyclones.
Figure 10 shows that there are strong seasonal variations in the background pressure gradient. On top of that, there is also strong interannual variability as well as subseasonal variability (not shown). All these together contribute to large variations of the low-frequency part of the pressure gradient. Since the total pressure gradient consists of the pressure gradient due to the synoptic cyclone and anticyclone together with the low-frequency part, this likely explains why the AR strength is not very highly correlated with either cyclone or anticyclone strength, since there is a large contribution of the lowfrequency part of the flow to the total pressure gradient. This low-frequency contribution to the background pressure gradient is even more pronounced in the $\mathrm{SH}$, possibly explaining why the correlations between AR intensity and cyclone/anticyclone strength are weaker there (Figs. 8b,d). 

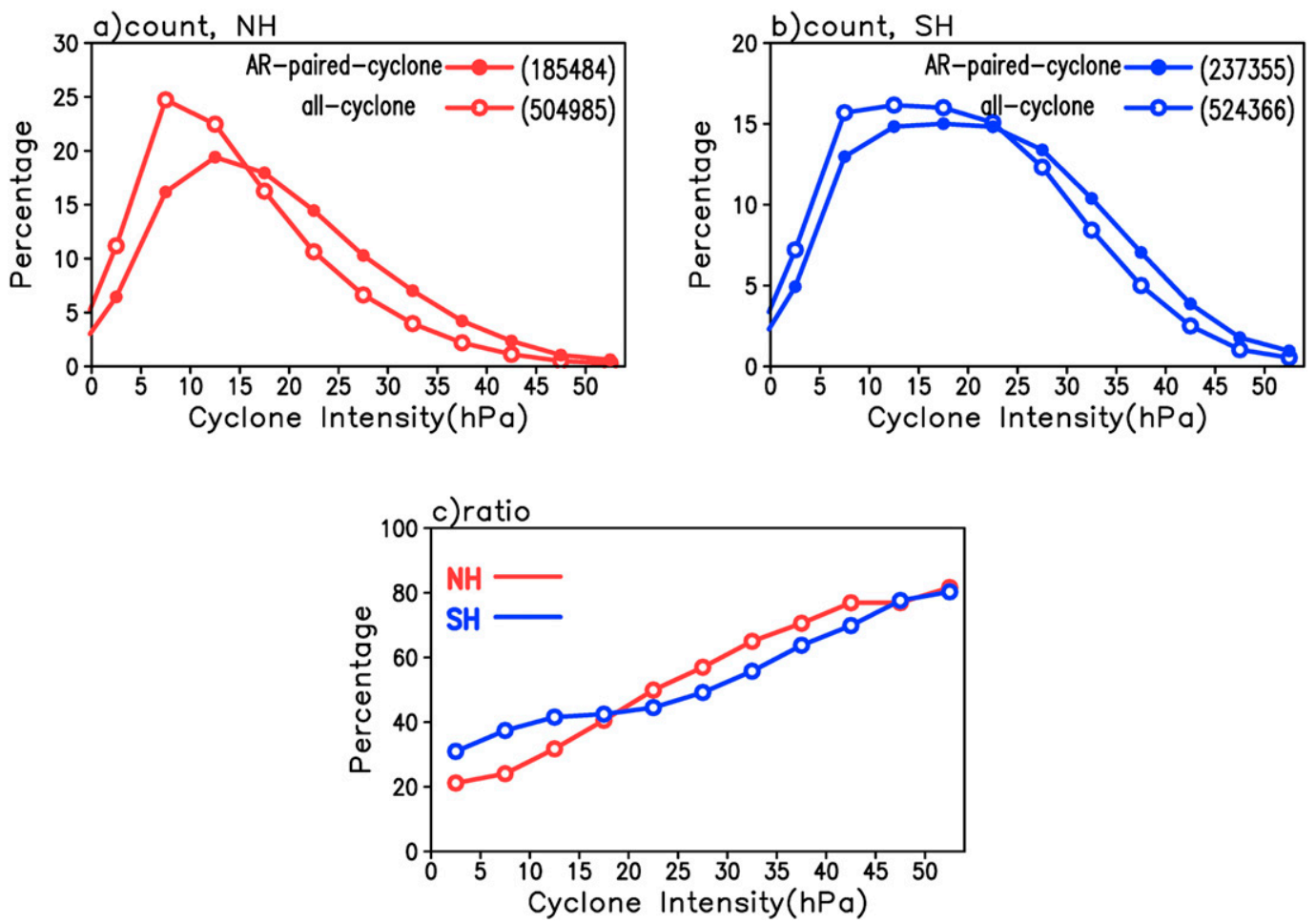

FIG. 11. The distributions of the number of AR-paired cyclones vs. all cyclones as a function of cyclone intensity, for (a) $\mathrm{NH}$ and (b) SH cases. The distributions are all normalized by their corresponding total numbers, which are listed in the parentheses at the top-right corner of the plot. (c) The percentage of AR-paired cyclones relative to all cyclones as a function of cyclone intensity.

\section{d. Count of AR-paired cyclones relative to all cyclones}

The analyses in previous sections demonstrate that the primary factor that determines the AR intensity is the magnitude of horizontal pressure gradient at the AR centroid, which is enhanced by the presence of the anticyclone in addition to the cyclone, and the cyclone intensity itself is not the dominant factor in determining the AR strength. Yet the cyclone intensity still influences AR occurrence as shown in the following analysis.

Figures 11a and 11b show the distribution of cyclone count as a function of cyclone intensity for AR-paired cyclones (closed circle) and all cyclones (open circle) within the $25^{\circ}-65^{\circ}$ latitude band in the $\mathrm{NH}$ and $\mathrm{SH}$, respectively. It is found that the intensity of both ARpaired cyclones and all cyclones spreads over a broad range, with the majority having anomalous intensity of $5-30 \mathrm{hPa}$. It is also noted that overall there are more weak cyclones in the $\mathrm{NH}$ mainly because cyclones are much weaker in the $\mathrm{NH}$ summer, while the seasonal cycle is not as marked in the SH (e.g., Chang et al. 2012; Guo et al. 2009). Furthermore, the distribution of ARpaired cyclone is shifted toward higher intensity when compared to the all-cyclone case for both the $\mathrm{NH}$ and
$\mathrm{SH}$, indicating that stronger cyclones are more likely to be accompanied by an AR. This is clearly illustrated in Fig. 11c, which shows the percentage of AR-paired cyclones relative to all cyclones as a function of cyclone intensity. The percentage monotonically increases from about $20 \%$ to $80 \%$ for both hemispheres. For cyclones with the anomalous intensity of about $30 \mathrm{hPa}$ or greater, more than half of them are accompanied by an AR. For very strong cyclones such as those with the anomalous intensity of $50 \mathrm{hPa}$ or greater, about $80 \%$ are accompanied by an AR. Thus ARs occur more often in stronger cyclones. This may also reflect the possibility that the AR can feed back onto the cyclone due to AR-associated diabatic processes.

These results suggest that the cyclone intensity influences the occurrence of AR significantly: the stronger the cyclone is, the stronger its circulation is and thus the more likely is the case that its associated moisture transport meets the threshold of an AR.

\section{Conclusions and discussion}

In this study, we have investigated statistical relations between ARs and extratropical cyclones/anticyclones 
from the analysis of 36 years (1979-2014) of objectively identified AR and cyclone datasets over the globe.

Atmospheric variables such as MSLP and TCWV are composited with respect to the AR centroids to examine the large-scale circulation and moisture structures around the AR. The composite analysis shows that the AR is closely related to the extratropical cyclone, and it locates in the warm sector of the cyclone, which is consistent with previous studies. In addition to the cyclone, a pronounced anticyclone is also found in the composite map, which has not been emphasized in previous studies. The presence of the cyclone to the poleward and westward side of the AR centroid and the anticyclone to its equatorward and eastward side results in a narrow corridor of strong horizontal pressure gradient that collocates with strong TCWV and low-level winds that manifest the AR conditions. This cyclone-AR-anticyclone configuration is robust in various $A R$ composites carried out for separate hemispheres, different ocean basins, and with regard to different AR strengths, confirming the importance of the anticyclone in the generation of the AR.

Furthermore, correlations between the AR intensity and its paired cyclone, anticyclone intensity, and the horizontal pressure gradient between the cyclone and anticyclone (approximated by the pressure gradient at the AR centroid) are calculated to demonstrate the importance of the anticyclone from a more quantitative perspective. It is found that correlations between the intensity of $\mathrm{AR}$ and its paired cyclone/anticyclone are all weak, or even negative, except for the case of ARcyclone correlations in the NH. The relatively weak correlation between the AR intensity and cyclone intensity suggests that the cyclone intensity is not the leading controlling factor to determine the strength of the AR, which is somewhat counterintuitive, but consistent with one very recent study (Sinclair and Dacre 2019). Instead, significant positive correlations are found between the AR intensity and the magnitude of the horizontal pressure gradient for all $\mathrm{NH}$ and $\mathrm{SH}$ cases and for different seasons. Our explanation is that although the cyclone is a necessary component to provide conditions favoring AR through the presence of its warm conveyor belt, the presence of an anticyclone downstream of the cyclone leads to stronger horizontal pressure gradient, and thus stronger poleward moisture transport, which makes it more easily qualified as an AR event. This is supported by the fact that not all of the cyclones have an associated ARs. In fact, our results show that only about half of them are accompanied by ARs. Our results also show that the anticyclone to the downstream equatorward side of the AR-associated cyclone is not a general feature of all cyclones-composites of all cyclones do not show such a feature. Thus, it is of interest to investigate what dynamical or synoptic conditions might favor the formation of such an anticyclone.

Furthermore, the importance of the horizontal pressure gradient in the generation of AR is not only observed in individual AR cases, but also in the climatology: the climatological mean maps show that ARs are most frequently located between the polar lows and the subtropical highs, and consistently migrate with the extension/ retreat of the subtropical high. This might provide possible insight for the predictability of ARs. For example, given cyclones with similar strength and moisture setting, whether an anticyclone develops downstream of the cyclone will result in quite different chances for the AR event. Given the fact that the large-scale circulation is more accurately represented in forecasts than moisturerelated factors, examining the possibility of strong pressure gradient/high pressure system in the path of cyclones could be an effective way to improve the prediction skill of the ARs.

Note that our study has focused on the dynamical factors contributing to the AR intensity, while in reality moisture-related processes also play important roles in determining the AR intensity. For example, we find that AR intensity is highly correlated with TCWV at the AR centroid. Nevertheless, the high moisture content at the AR centroid is brought there by the strong poleward flow due to the strong pressure gradient between the cyclone and anticyclone, and thus is clearly not independent of the dynamical factors. The combined impacts and interactions between large-scale dynamics and moist processes should be examined in future studies.

One caveat we should be aware of is that our results may depend somewhat on the objective detection algorithms for both the ARs and the cyclones/anticyclones. Nevertheless, the algorithms used in this study have been carefully compared with other detection algorithms and have been validated against observations when possible. Both of them have been widely used in the research community. Furthermore, our analysis is based on datasets over the globe and spanning over a few decades. With such a large number of samples (on the order of $10^{4}$ ), random errors in the center location and intensity of the ARs and cyclones/anticyclones are largely cancelled out, which adds further confidence to our results. Also, our composite and correlation analysis have been carried out for different ocean basins, with respect to different $A R$ strengths, and for different seasons, in order to provide information from different perspectives. Nevertheless, quantifying the sensitivity of our results to different detection algorithms is desirable in the future.

As discussed above, our results raise several further questions. For example, what is the reason for the poor correlation between the AR and cyclone intensity in the 
$\mathrm{SH}$ ? Does it represent the real situation in the $\mathrm{SH}$, or is it related to the difficulties in determining the strength of the SH cyclones? Apart from the pressure gradient, what other factors are important in determining AR intensity? How do large-scale dynamics and moisture processes interact? More efforts are needed to tackle these questions in the future. Also, it will be interesting to examine how well our findings based on the reanalysis are represented in climate models. Analyses for addressing some of these issues are part of our ongoing and future studies.

Acknowledgments. The authors thank four reviewers whose comments have helped to clarify this paper. This research is supported by National Science Foundation (NSF) Grant AGS-1347132. Computing resources were provided partly by NCAR's CISL sponsored by NSF and partly by the HPC systems at the Texas A\&M University (College Station and Corpus Christi). Author Shinoda was also supported by NOAA Grants NA15OAR431074 and NA17OAR4310256, NSF Grant OCE-1658218, NASA Grant NNX17AH25G, and DoD Grant W911NF-20-10309. Authors Waliser and Guan were supported by the NASA Energy and Water Cycle Study (NEWS) program and the California Department of Water Resources. Waliser's contribution to this study was carried out on behalf of the Jet Propulsion Laboratory, California Institute of Technology, under a contract with NASA. Author Chang was supported by NASA Grant NNX16AG32G.

\section{REFERENCES}

AMS, 2017: Atmospheric river. Glossary of Meteorology, American Meteorological Society, https:/glossary.ametsoc.org/ wiki/Atmospheric_river.

Bao, J.-W., S. A. Michelson, P. J. Neiman, F. M. Ralph, and J. M Wilczak, 2006: Interpretation of enhanced integrated water vapor bands associated with extratropical cyclones: Their formation and connection to tropical moisture. Mon. Wea. Rev., 134, 1063-1080, https://doi.org/10.1175/MWR3123.1.

Boutle, I. A., R. J. Beare, S. E. Belcher, A. R. Brown, and R. S Plant, 2010: The moist boundary layer under a mid-latitude weather system. Bound.-Layer Meteor., 134, 367-386, https:// doi.org/10.1007/s10546-009-9452-9.

Brands, S., J. Gutiérrez, and D. San-Martín, 2016: Twentieth-century atmospheric river activity along the west coasts of Europe and North America: Algorithm formulation, reanalysis uncertainty and links to atmospheric circulation patterns. Climate Dyn., $\mathbf{4 8}$, 2771-2795, https://doi.org/10.1007/s00382-016-3095-6.

Catto, J. L., and S. Pfahl, 2013: The importance of fronts for extreme precipitation. J. Geophys. Res. Atmos., 118, $10791-$ 10 801, https://doi.org/10.1002/jgrd.50852.

Chang, E. K. M., and S. Song, 2006: The seasonal cycles in the distribution of precipitation around cyclones in the western North Pacific and Atlantic. J. Atmos. Sci., 63, 815-839, https:// doi.org/10.1175/JAS3661.1.

- Y. Guo, and X. Xia, 2012: CMIP5 multimodel ensemble projection of storm track change under global warming.
J. Geophys. Res., 117, D23118, https://doi.org/10.1029/ 2012JD018578.

Dacre, H. F., P. A. Clark, O. Martinez-Alvarado, M. A. Stringer, and D. A. Lavers, 2015: How do atmospheric rivers form? Bull. Amer. Meteor. Soc., 96, 1243-1255, https://doi.org/ 10.1175/BAMS-D-14-00031.1.

—, O. Martínez-Alvarado, and C. O. Mbengue, 2019: Linking atmospheric rivers and warm conveyor belt airflows. J. Hydrometeor., 20, 1183-1196, https://doi.org/10.1175/ JHM-D-18-0175.1.

Dee, D. P., and Coauthors, 2011: The ERA-Interim reanalysis: Configuration and performance of the data assimilation system. Quart. J. Roy. Meteor. Soc., 137, 553-597, https://doi.org/ 10.1002/qj.828.

Donohoe, A., and D. S. Battisti, 2009: The amplitude asymmetry between synoptic cyclones and anticyclones: Implications for filtering methods in feature tracking. Mon. Wea. Rev., 137, 3874-3887, https://doi.org/10.1175/2009MWR2837.1.

Eiras-Barca, J., S. Brands, and G. Miguez-Macho, 2016: Seasonal variations in North Atlantic atmospheric river activity and associations with anomalous precipitation over the Iberian Atlantic Margin. J. Geophys. Res. Atmos., 121, 931-948, https://doi.org/10.1002/2015JD023379.

—, A. M. Ramos, J. G. Pinto, R. M. Trigo, M. L. R. Liberato, and G. Miguez-Macho, 2018: The concurrence of atmospheric rivers and explosive cyclogenesis in the North Atlantic and North Pacific basins. Earth Syst. Dyn., 9, 91-102, https:// doi.org/10.5194/esd-9-91-2018.

Gimeno, L., R. Nieto, M. Vázquez, and D. A. Lavers, 2014: Atmospheric rivers: A mini-review. Front. Earth Sci., 2, https://doi.org/10.3389/feart.2014.00002.

Guan, B., and D. E. Waliser, 2015: Detection of atmospheric rivers: Evaluation and application of an algorithm for global studies. J. Geophys. Res. Atmos., 120, 12 514-12 535, https://doi.org/ 10.1002/2015JD024257.

— , N. P. Molotch, D. E. Waliser, E. J. Fetzer, and P. J. Neiman, 2010: Extreme snowfall events linked to atmospheric rivers and surface air temperature via satellite measurements. Geophys. Res. Lett., 37, L20401, https://doi.org/10.1029/ 2010GL044696.

,,,$----\longrightarrow$, and -2013 : The 2010/2011 snow season in California's Sierra Nevada: Role of atmospheric rivers and modes of large-scale variability. Water Resour. Res., 49, 67316743, https://doi.org/10.1002/wrcr.20537.

, D. E. Waliser, and F. M. Ralph, 2018: An intercomparison between reanalysis and dropsonde observations of the total water vapor transport in individual atmospheric rivers. J. Hydrometeor., 19, 321-337, https://doi.org/10.1175/JHMD-17-0114.1.

Guo, Y., E. K. M. Chang, and S. S. Leroy, 2009: How strong are the Southern Hemisphere storm tracks? Geophys. Res. Lett., 36, L22806, https://doi.org/10.1029/2009GL040733.

, T. Shinoda, J. Lin, and E. K. M. Chang, 2017: Variations of Northern Hemisphere storm track and extratropical cyclone activity associated with the Madden-Julian oscillation. J. Climate, 30, 4799-4818, https://doi.org/10.1175/JCLI-D-16-0513.1.

Haurwitz, B., and J. M. Austin, 1944: Climatology, McGraw-Hill, $410 \mathrm{pp}$.

Hodges, K. I., 1999: Adaptive constraints for feature tracking. Mon. Wea. Rev., 127, 1362-1373, https://doi.org/10.1175/15200493(1999)127<1362:ACFFT>2.0.CO;2.

Hoskins, B. J., and K. I. Hodges, 2002: New perspectives on the Northern Hemisphere winter storm tracks. J. Atmos. Sci., 59, 
1041-1061, https://doi.org/10.1175/1520-0469(2002)059<1041: NPOTNH $>2.0 . \mathrm{CO} ; 2$.

Lakshmi, D. D., A. N. V. Satyanarayana, and A. Chakraborty, 2019: Assessment of heavy precipitation events associated with floods due to strong moisture transport during summer monsoon over India. J. Atmos. Sol.-Terr. Phys., 189, 123-140, https://doi.org/10.1016/j.jastp.2019.04.013.

Lavers, D. A., and G. Villarini, 2013: The nexus between atmospheric rivers and extreme precipitation across Europe. Geophys. Res. Lett., 40, 3259-3264, https://doi.org/10.1002/ grl.50636.

$\longrightarrow,-$, R. P. Allan, E. F. Wood, and A. J. Wade, 2012: The detection of atmospheric rivers in atmospheric reanalyses and their links to British winter floods and the large-scale climatic circulation. J. Geophys. Res., 117, D20106, https://doi.org/ 10.1029/2012JD018027.

_, M. J. Rodwell, D. S. Richardson, F. M. Ralph, J. D. Doyle, C. A. Reynolds, V. Tallapragada, and F. Pappenberger, 2018: The gauging and modeling of rivers in the sky. Geophys. Res. Lett., 45, 7828-7834, https://doi.org/10.1029/ 2018 GL079019.

Leung, L. R., and Y. Qian, 2009: Atmospheric rivers induced heavy precipitation and flooding in the western U.S. simulated by the WRF regional climate model. Geophys. Res. Lett., 36, L03820, https://doi.org/10.1029/2008GL036445.

Neiman, P. J., F. M. Ralph, G. A. Wick, Y.-H. Kuo, T.-K. Wee, Z. Ma, G. H. Taylor, and M. D. Dettinger, 2008a: Diagnosis of an intense atmospheric river impacting the Pacific Northwest: Storm summary and offshore vertical structure observed with COSMIC satellite retrievals. Mon. Wea. Rev., 136, 4398-4420, https://doi.org/10.1175/2008MWR2550.1.

,,,-- J. D. Lundquist, and M. D. Dettinger, 2008b: Meteorological characteristics and overland precipitation impacts of atmospheric rivers affecting the west coast of North America based on eight years of SSM/I satellite observations. J. Hydrometeor., 9, 22-47, https://doi.org/ 10.1175/2007JHM855.1.

_ L. J. Schick, F. M. Ralph, M. Hughes, and G. A. Wick, 2011: Flooding in western Washington: The connection to atmospheric rivers. J. Hydrometeor., 12, 1337-1358, https://doi.org/ 10.1175/2011JHM1358.1.

Newell, R. E., and Y. Zhu, 1994: Tropospheric rivers: A one-year record and a possible application to ice core data. Geophys. Res. Lett., 21, 113-116, https://doi.org/10.1029/93GL03113.

Payne, A. E., and G. Magnusdottir, 2014: Dynamics of landfalling atmospheric rivers over the North Pacific in 30 years of MERRA reanalysis. J. Climate, 27, 7133-7150, https://doi.org/ 10.1175/JCLI-D-14-00034.1.

Ralph, F. M., and M. D. Dettinger, 2011: Storms, floods, and the science of atmospheric rivers. Eos, Trans. Amer. Geophys. Union, 92, 265-266, https://doi.org/10.1029/2011EO320001.

_ P. J. Neiman, and G. A. Wick, 2004: Satellite and CALJET aircraft observations of atmospheric rivers over the eastern North Pacific Ocean during the winter of 1997/98. Mon. Wea. Rev., 132, 1721-1745, https://doi.org/10.1175/1520-0493(2004) $132<1721$ :SACAOO $>2.0$. CO 2 .

,,,--- S. I. Gutman, M. D. Dettinger, D. R. Cayan, and A. B. White, 2006: Flooding on California's Russian River: Role of atmospheric rivers. Geophys. Res. Lett., 33, L13801, https://doi.org/10.1029/2006GL026689.

— , and Coauthors, 2018: ARTMIP-early start comparison of atmospheric river detection tools: How many atmospheric rivers hit northern California's Russian River watershed?
Climate Dyn., 52, 4973-4994, https://doi.org/10.1007/s00382018-4427-5.

Ramos, A. M., R. M. Trigo, M. L. R. Liberato, and R. Tomé, 2015: Daily precipitation extreme events in the Iberian Peninsula and its association with atmospheric rivers. J. Hydrometeor. 16, 579-597, https://doi.org/10.1175/JHM-D-14-0103.1.

Rutz, J. J., W. J. Steenburgh, and F. M. Ralph, 2014: Climatological characteristics of atmospheric rivers and their inland penetration over the western United States. Mon. Wea. Rev., 142, 905-921, https://doi.org/10.1175/MWR-D-13-00168.1.

Sellars, S. L., B. Kawzenuk, P. Nguyen, F. M. Ralph, and S. Sorooshian, 2017: Genesis, pathways, and terminations of intense global water vapor transport in association with largescale climate patterns. Geophys. Res. Lett., 44, 12 465-12 475, https://doi.org/10.1002/2017GL075495.

Shields, C. A., and Coauthors, 2018: Atmospheric River Tracking Method Intercomparison Project (ARTMIP): Project goals and experimental design. Geosci. Model Dev., 11, 2455-2474, https://doi.org/10.5194/gmd-11-2455-2018.

Sinclair, V. A., and H. F. Dacre, 2019: Which extratropical cyclones contribute most to the transport of moisture in the Southern Hemisphere? J. Geophys. Res. Atmos., 124, 2525-2545, https:// doi.org/10.1029/2018JD028766.

Starr, V. P., 1942: Basic Principles of Weather Forecasting. Harper and Brothers, 299 pp.

Trenberth, K. E., 1991: Storm tracks in the Southern Hemisphere. J. Atmos. Sci., 48, 2159-2178, https://doi.org/10.1175/15200469(1991)048<2159:STITSH>2.0.CO;2.

Viale, M., and M. N. Nunez, 2011: Climatology of winter orographic precipitation over the subtropical central Andes and associated synoptic and regional characteristics. J. Hydrometeor., 12, 481-507, https://doi.org/10.1175/ 2010JHM1284.1.

Waliser, D. E., and B. Guan, 2017: Extreme winds and precipitation during landfall of atmospheric rivers. Nat. Geosci., 10, 179-183, https://doi.org/10.1038/ngeo2894.

Warner, M. D., C. F. Mass, and E. P. Salathé Jr., 2012: Wintertime extreme precipitation events along the Pacific Northwest coast: Climatology and synoptic evolution. Mon. Wea. Rev., 140, 2021-2043, https://doi.org/10.1175/MWR-D-11-00197.1.

$\longrightarrow, \ldots$, and —., 2015: Changes in winter atmospheric rivers along the North American west coast in CMIP5 climate models. J. Hydrometeor., 16, 118-128, https://doi.org/10.1175/ JHM-D-14-0080.1.

Yang, Y., T. Zhao, G. Ni, and T. Sun, 2018: Atmospheric rivers over the Bay of Bengal lead to northern Indian extreme rainfall. Int. J. Climatol., 38, 1010-1021, https://doi.org/ 10.1002/joc.5229.

Zhang, Z., F. M. Ralph, and M. Zheng, 2019: The relationship between extratropical cyclone strength and atmospheric river intensity and position. Geophys. Res. Lett., 46, 1814-1823, https://doi.org/10.1029/2018GL079071.

Zhou, Y., H. Kim, and B. Guan, 2018: Life cycle of atmospheric rivers: Identification and climatological characteristics. J. Geophys. Res. Atmos., 123, 12 715-12 725, https://doi.org/ 10.1029/2018JD029180.

Zhu, Y., and R. E. Newell, 1994: Atmospheric rivers and bombs. Geophys. Res. Lett., 21, 1999-2002, https://doi.org/10.1029/ 94GL01710.

— from atmospheric rivers. Mon. Wea. Rev., 126, 725-735, https://doi.org/10.1175/1520-0493(1998)126<0725:APAFMF $>$ 2.0. $\mathrm{CO} ; 2$. 